
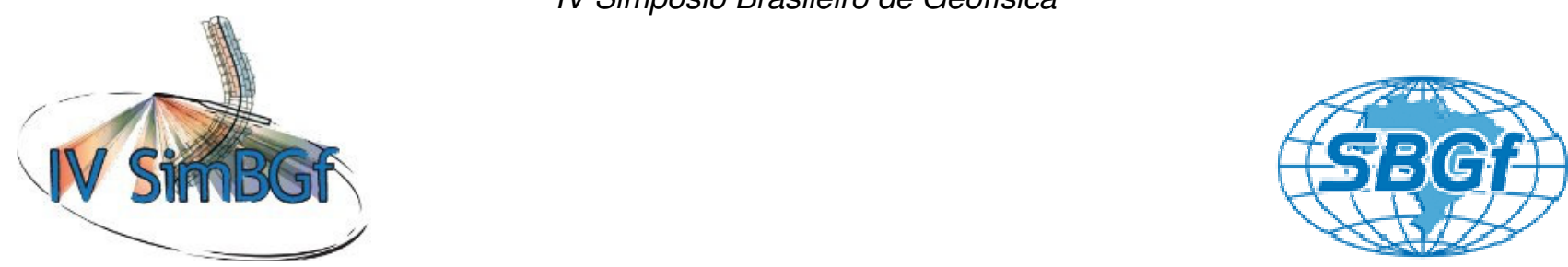

\title{
A influência do regolito no mapeamento do embasamento rochoso através de métodos geofísicos.
}

Eduardo F. Henrique, RECONSULT GEOFÍSICA

Copyright 2008, SBGf - Sociedade Brasileira de Geofísica

Este texto foi preparado para a apresentação no IV Simpósio Brasileiro de Geofísica, Belém, 14 a 17 de novembro de 2010. Seu conteúdo foi revisado pelo Comitê Técnico do IV SimBGf, mas não necessariamente representa a opinião da SBGf ou de seus associados. E proibida a reprodução total ou parcial deste material para propósitos comerciais sem prévia autorização da SBGf.

\section{Resumo}

A aplicação da geofísica terrestre na pesquisa mineral visa na maioria das vezes imagear o embasamento rochoso que está coberto por um regolito de características físicas e químicas muito variáveis. O geocientista que trabalha com exploração mineral deve saber distinguir no dado geofísico as respostas proveniente da cobertura, das respostas do embasamento. Este artigo discute as principais características físicas dos regolitos no Brasil e a influência das coberturas nos métodos geofísicos mais tradicionais na mineração. Exemplos práticos são mostrados para ilustrar as discussões.

\section{Introdução}

Pelas dimensões continentais do território brasileiro, a heterogeneidade das coberturas sobre o embasamento rochoso é enorme. Conseqüentemente a influência dela nos dados geofísicos terrestres é bem variável. Esta variabilidade gera muita confusão na interpretação de dados geofísicos terrestres ou mesmo aéreos. Regiões como a mesma geologia no embasamento, mas com coberturas diferentes geram imagens geofísicas também diferentes.

A distinção clara entre o que é resposta vinda do embasamento e da cobertura é fundamental para quem trabalha em pesquisa mineral no Brasil. Para isto é necessário um entendimento mesmo que básico das características físicas das coberturas de onde foi adquirido o dado geofísico e como estas propriedades interferem na metodologia aplicada.

\section{Características das coberturas no Brasil}

No caso específico do Brasil, os geocientistas se deparam principalmente com dois tipos de coberturas, sedimentos terciários e quaternários e mantos de intemperismo laterizados ou não devido ao regime climático tropical e sub-tropical.

As coberturas da era Cenozóica são na maioria das vezes formadas por sedimentos muitas vezes inconsolidados arenosos, areno-argilosos, com níveis de cascalhos e lateritas.

O manto de intemperismo ou regolito é como um capeamento natural das rochas (manto de intemperismo), inconsolidado, composto por fragmentos de rocha e solo, incluindo solo transportado, solo autóctone e depósitos residuais. A figura 1 mostra um exemplo típico de manto de intemperismo em regime tropical.

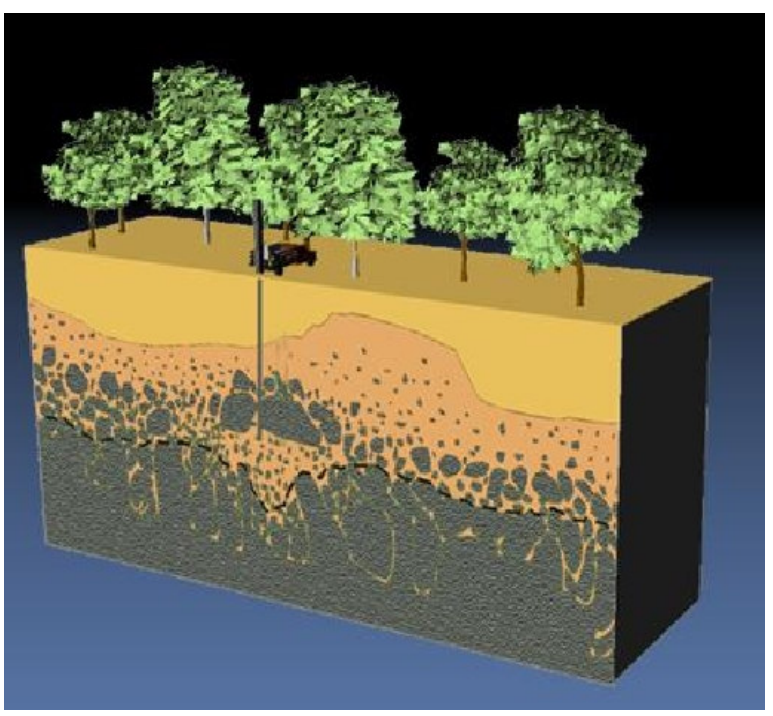

Figura 1: Desenho mostrando um típico perfil do manto de intemperismo em uma região tropical. (Modificado a partir de Francke, 2010).

Palacky e Kadekaru (1979) foram um dos primeiros a discutir os efeitos do regolito brasileiro em medidas geofísicas. Através de sondagens elétricas e levantamentos eletromagnéticos em distritos mineiros em cinco estados brasileiros (Rio Grande do Sul, Minas Gerais, Goiás, Bahia e Pará) eles concluem que nas regiões tropicais e sub-tropicais a camada de intemperismo varia de 10 a 80 metros de espessura e possuí condutividades moderadas. Aluviões salinos altamente condutivos foram encontrados somente no semi-árido nordestino. Para os autores, a excessiva espessura das coberturas e o processo de laterização dos sulfetos maciços representam o maior obstáculo para a aplicação de levantamentos EM aerotransportados.

West e Whitherly (1995) conduziram medidas de polarização induzida e resistividade usando um arranjo dipolo-dipolo com espaçamentos de 5, 10, 40 e 60 metros para estudar as propriedades físicas do regolito sobre um depósito de ouro em Goiás. Os resultados mostram que há uma variação suave de cargabilidade e resistividade da superfície para o embasamento. Eles concluem que as respostas observadas são provavelmente oriundas das argilas. 
Francke (2010) mostra um perfil de GPRM (ground penetration radar) executado sobre um depósito de níquel laterítico no estado do Pará (figura 2). Os resultados amarrados com sondagens diretas mostram que a camada de regolito chega até 60 metros na área de estudo.

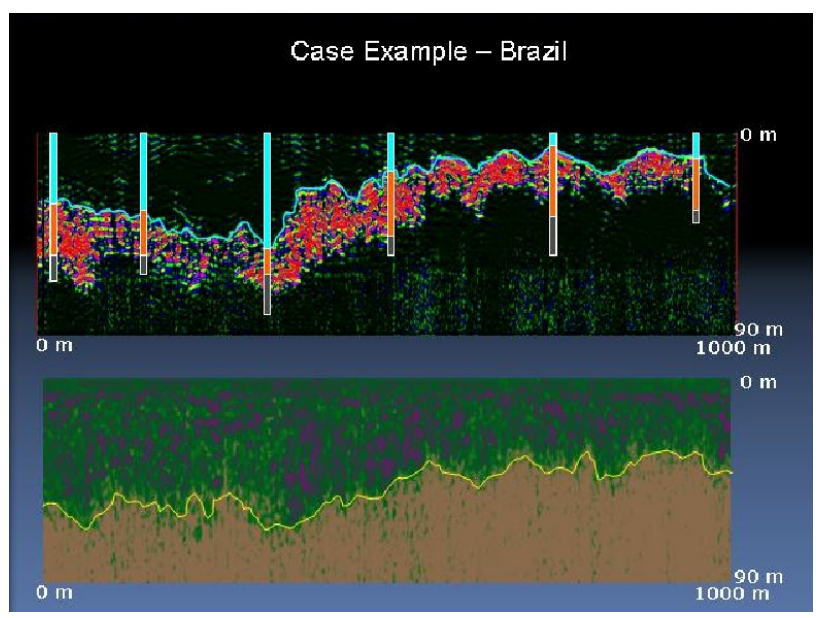

Figura 2: Perfil de GPR no sul do Pará para estudo de deposto de níquel laterítico. O imageamento mostra que a espessura da cobertura pode chegar a 60 metros (Modificado a partir de Francke, 2010).

A generalização em um país tão grande como no Brasil é sempre perigosa. Contudo, levantamentos aerogeofísicos eletromagnéticos no Brasil têm mostrado que os processos de intemperismo e laterização no Brasil dificilmente geram barreiras intransponíveis para os métodos geofísicos. O maior problema está na grande variabilidade da espessura e das litologias que constituem o regolito. Arranjos geofísicos que funcionam em uma determinada área podem não ser apropriados para outra área. Portanto, um entendimento das características especificas do regolito da área de estudo e seus efeitos nos métodos geofísicos é fundamental para a otimização dos ensaios a serem aplicados.

\section{Método geofísico e Influência das coberturas}

Dependendo da metodologia geofísica selecionada, a influência das coberturas no dado pode ser mais pronunciada ou não. Neste artigo optou-se em discutir os métodos mais utilizados na exploração mineral, que são: a magnetometria, a gamaespectrometria, polarização induzida (IP), a resistividade e a eletromagnetismo.

\section{Método magnético}

Segundo Doyle e Lindeman (1985), dados aeromagnéticos são menos afetados por camadas de intemperismo do que a maioria dos métodos geofísicos. Este fato aliado a grande profundidade de investigação talvez seja um dos motivos da popularidade do método aeromagnético como ferramenta básica de mapeamento geológico para diversos serviços geológicos no mundo, incluindo a CPRM no Brasil.

Contudo, freqüentemente a magnetometria terrestre, devido a pouca distância entre o sensor e o solo, é afetada pela presença de minerais magnéticos no regolito, gerando perfis magnéticos extremamente ruidosos que suprimem as anomalias de interesse localizadas no embasamento local. A figura 3 mostra um exemplo onde um levantamento magnético terrestre foi afetado pela presença de lateritas aflorantes (figura 4) na malha levantada no norte de Goiás. Como conseqüência, a imagem magnética dos dados não editados mostra quase que exclusivamente as zonas de lateritas aflorantes e sub-aflorantes.

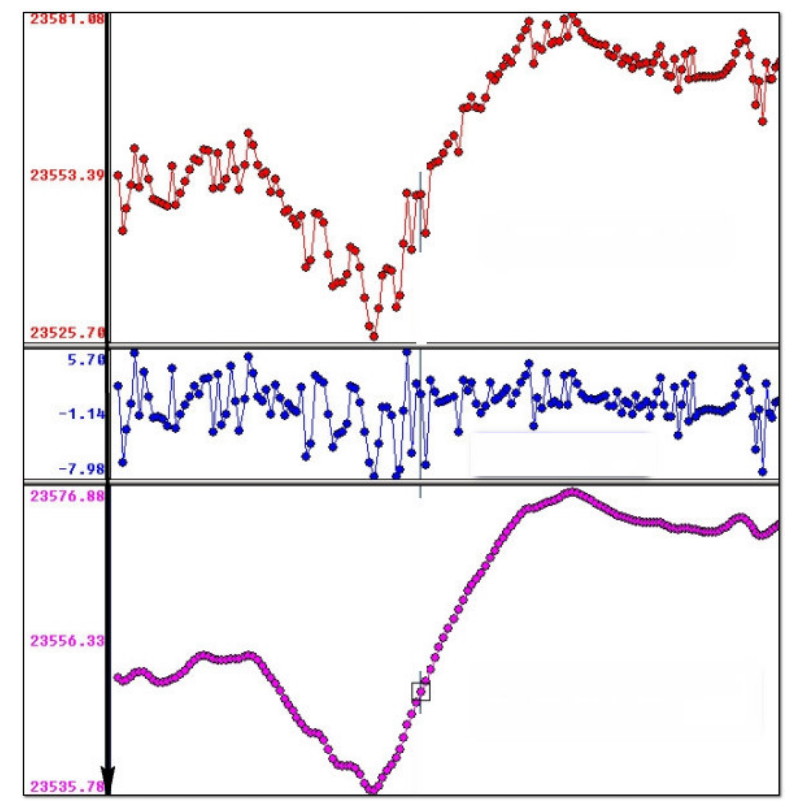

Figura 3 Perfil magnético sobre lateritas ricas em magnetita como mostrado na figura 4. de cima para baixo, anomalia magnética contaminada por ruído geológico; Ruído geológico isolado do dado; Anomalia magnética sem o efeito da cobertura.

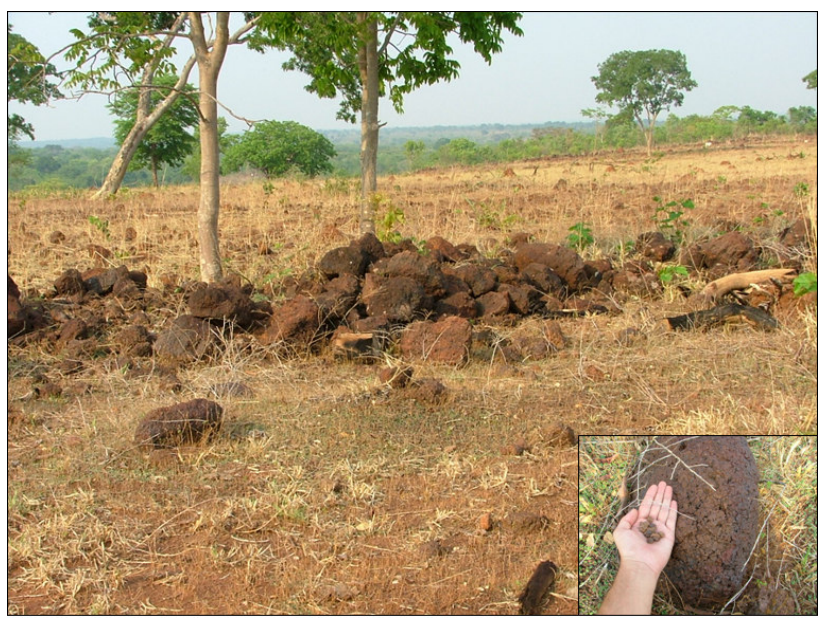

Figura 4 Foto das lateritas causadoras do ruído magnético mostrado na figura 3. No detalhe são mostrados os cristais de magnetitas. 


\section{Método gamaespectrométrico}

Em contraste com método magnético, 0 método gamaespectrométrico é por si só um excelente mapeador da cobertura, devido a sua baixíssima profundidade de investigação, que é da ordem de trinta centímetros. A popularidade deste método entre os geólogos é principalmente devido a este fato. Ele reflete o que é possível ver em superfície, corroborando com a técnica de mapeamento geológico superficial.

Conforme citado por vários autores, a interpretação das imagens gamaespectrométricas deve sempre levar em conta os aspectos topográficos e da cobertura vegetal da área de estudo. Na região norte do Brasil, áreas que foram voadas antes de serem desmatadas e depois apresentam gamaespectrométricas muito diferentes 0 que pode confundir o intérprete.

Brandão et at. (2010) utilizaram imagens gamaespectrométricas no estudo de regolitos no norte de Goiás. Eles utilizaram o canal de potássio como indicativo do grau de exposição das rochas do embasamento e conseqüentemente da efetividade dos métodos de geologia de superfície e geoquímica de solos na exploração mineral.

A simples comparação entre imagens aeromagnéticas e aerogamaespectrométricas pode levar a conclusões importantes sobre a cobertura da área de estudo. $O$ fato de existir uma boa correlação entre as imagens magnéticas e gamaespectrométricas, é um forte indício que o embasamento rochoso é sub-aflorante e/ou que os solos são do tipo residual. Nestas áreas as metodologias tradicionais como mapeamento de superfície e geoquímica de solos normalmente são muito eficazes na pesquisa mineral.

Com uma freqüência maior do que a esperada, no Brasil existem diversas áreas onde as imagens aerogamaespectrométricas são muito diferentes das imagens aeromagnéticas. Nestes locais as técnicas tradicionais de mapeamento geológico de superfície e geoquímicas não funcionam. Nestes casos o mapeamento do embasamento rochoso deverá ser conduzido através da integração entre dados de sondagens e de imagens aerogeofísicas.

\section{Método de polarização induzida}

O entendimento dos efeitos das coberturas neste importante método na pesquisa mineral é fundamental para o correto imageamento do embasamento rochoso. As características das coberturas definem principalmente a efetividade e a profundidade de investigação deste método.

O maior limitador do método de polarização induzida (IP), como nos métodos elétricos em geral, são coberturas condutivas e/ou extremamente argilosas. As coberturas condutivas, como zonas percoladas por água salgada ou constituídas por minerais carbonosos, por exemplo, funcionam como uma barreira para a passagem da corrente elétrica que gerará o efeito de cargabilidade. Portanto, quando as correntes elétricas não conseguem penetrar no embasamento rochoso, não há como mapeá- lo. Um exemplo é mostrado na figura 5 onde o método IP falhou em imagear o substrato rochoso, pois a condutividade do regolito é muito baixa (> 30 ohm.m) devido a presença de material carbonoso saturado em água.

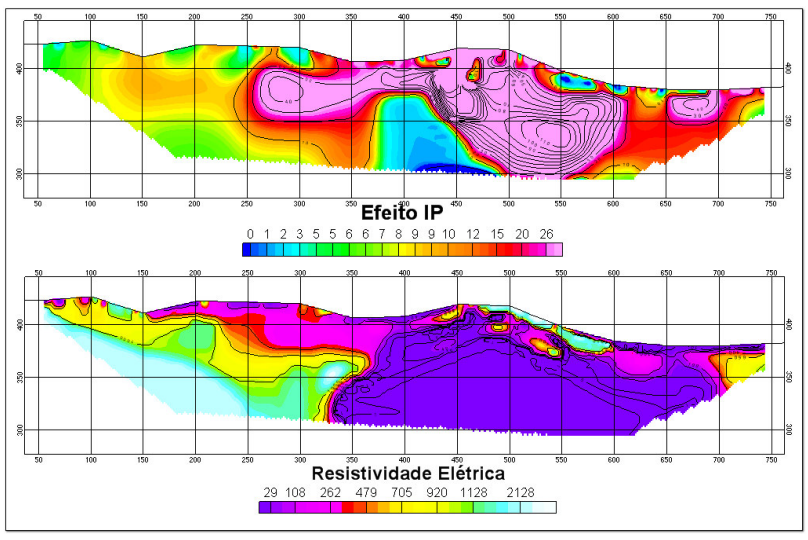

Figura 5 Levantamento IP e de resistividade sobre regolito carbonoso. No painel de cima o resultado da inversão dos dados de cargabilidade, no painel de baixo o resultado da inversão de resistividade elétrica. Ambos os métodos falharam em imagear o embasamento.

Em platôs no norte do Pará, um levantamento de polarização induzida também não obteve sucesso para imagear o embasamento, apesar da escolha criteriosa do arranjo de eletrodos (pólo-dipolo com dipolo de 75 metros entre eletrodos e dez níveis de investigação). A figura 6 mostra uma das seções de IP obtidas. Sondagens mostram que sobre o embasamento existe uma cobertura essencialmente argilosa com até 50 metros de espessura. Neste caso, a forte polarização das argilas do regolito impossibilitou o imageamento na profundidade desejada, que era de cerca de 200 metros abaixo da superfície.

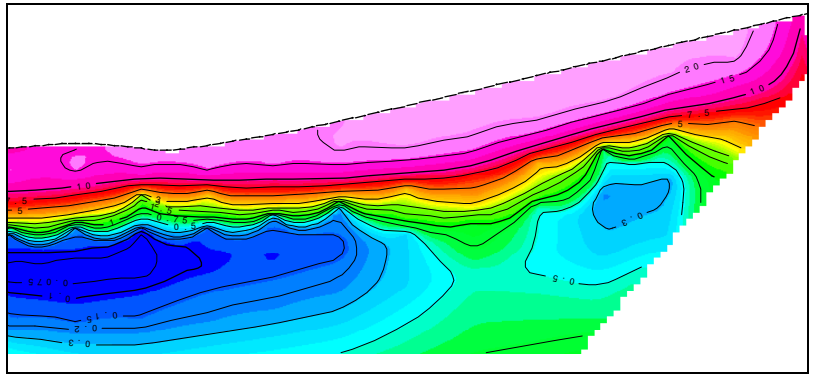

Figura 6 Seção invertida de cargabilidade em uma área onde sobre o embasamento rochoso existe um pacote de cerca de 50 metros de argilas. Devido ao efeito IP dos argilo minerais presentes no regolito, o levantamento não foi eficiente no mapeamento do embasamento.

\section{Método de eletrorresistividade}

$\mathrm{Na}$ exploração mineral normalmente o levantamento por eletrorresistividade é feito simultaneamente com 0 levantamento IP. Portanto, os arranjos de eletrodos mais utilizados o dipolo-dipolo, pólo-dipolo e pólo-pólo. Nestes arranjos o método eletrorresistivo, como o IP, também 
não funciona de forma apropriada quando o regolito é condutivo.

Antes do uso intensivo de algoritmos de inversão de dados de IP e resistividade, as pseudo-seções de resistividade nos arranjos tipo dipolo-dipolo eram praticamente impossíveis de se interpretar corretamente, devido principalmente a grande variação da resistividade elétrica do regolito. Pequenas lentes condutivas próximas a superfície mudam completamente os perfis de resistividade aparente, mesmo quando o embasamento manteve-se eletricamente homogêneo.

Agora com as seções de resistividade invertidas em profundidade, a informação de resistividade e é muitas vezes tão relevante quando a de IP na exploração. Mineral. Além de posicionar tanto lateralmente como em profundidade os condutores e resistores no embasamento, o processo de inversão elétrica permite uma separação clara do sinal oriundo da cobertura do sinal do embasamento. As figuras $7 \mathrm{~A}$ e $7 \mathrm{~B}$ mostram em visões 3D duas situações onde em (A) as respostas elétricas são dominadas pela resposta de um regolito condutivo. Em (B) as respostas elétricas de zero a cinqüenta metros de profundidade foram retiradas, mostrando a distribuição de resistividade do embasamento local. Somente assim é possível visualizar em planta uma importante estrutura condutiva que condiciona as mineralizações do prospecto.

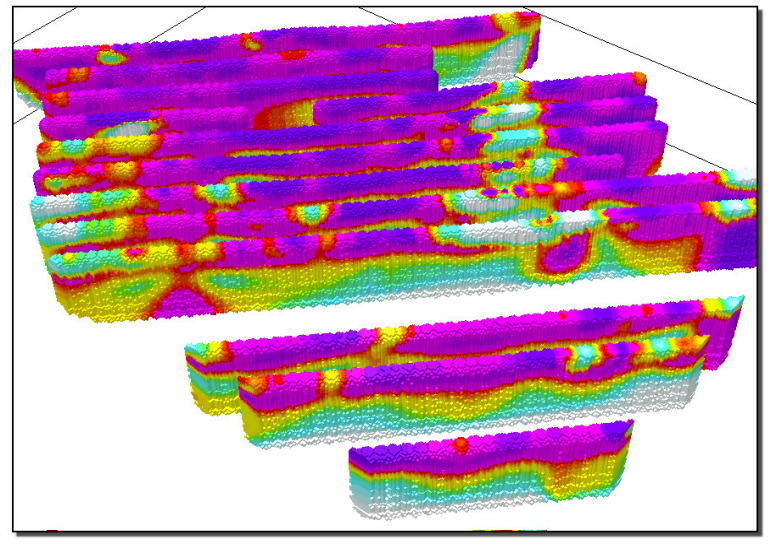

(A)

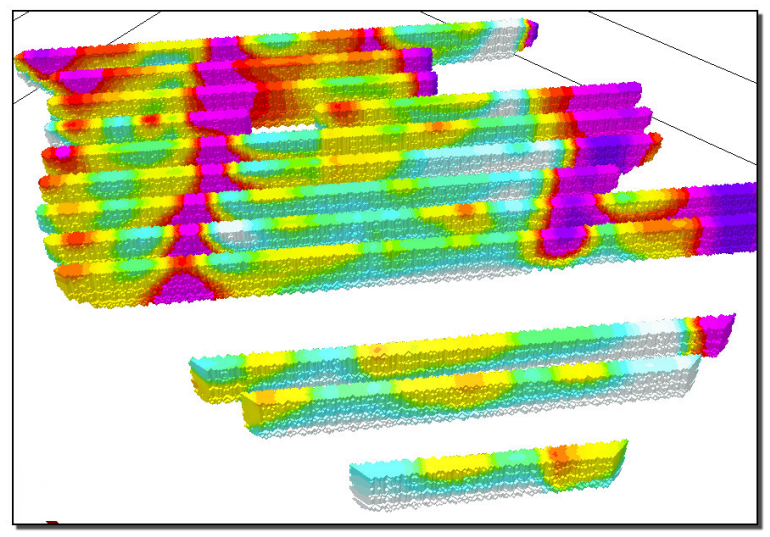

(B)
Figura 7 Visões $3 D$ de seções de resistividade invertida com as mesmas tabelas de cores utilizadas na figura 5. Em (A) os modelos são mostrados com a influência do regolito condutivo. $\mathrm{Em}(B)$ as respostas elétricas de 0 a 50 metros de profundidade foram suprimidas e portanto são realçadas estruturas condutivas no embasamento.

\section{Método eletromagnético}

Como na resistividade elétrica, o método eletromagnético (EM) é também muito suscetível as variações de condutividade do regolito. Os levantamentos no domínio da freqüência (FEM) também têm suas profundidades de investigação bem limitas em regiões de cobertura condutiva, como ocorre na técnica de eletrorresistividade. Já os levantamentos no domínio do tempo (TEM), dependendo das janelas de tempo utilizadas, a cobertura condutiva pode ser ultrapassada para o imageamento do embasamento.

Contudo mesmo no TEM, a separação entre as respostas vindas do embasamento e oriundas do regolito não é fácil. Sendo talvez este processo uma das maiores fontes de erros na interpretação e na seleção de alvos TEM. A localização de condutores no embasamento coberto por regolito resistivo é relativamente fácil, como mostrado no exemplo da figura 8. Já quando há uma cobertura condutiva, as respostas de possíveis condutores ficam mascaradas pelas respostas do regolito (figura 9) nos sistemas que só lêem a variação dB/dt.

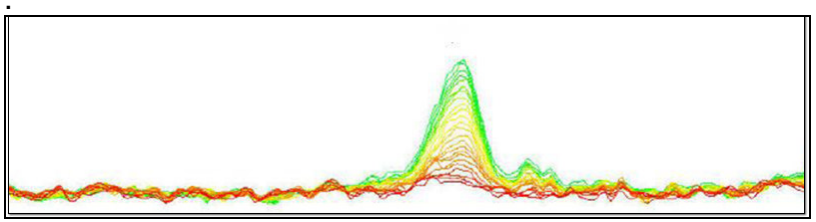

Figura 8 Perfil EM (dB/dt) sobre um condutor no embasamento coberto por um regolito resistivo..

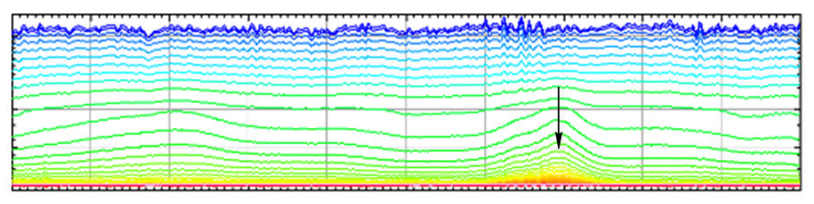

Figura 9 Perfil EM (dB/dt) sobre um condutor (destacado pela seta preta) no embasamento coberto por um regolito condutivo.

\section{A importância das inversões no mapeamento do embasamento}

A aplicação de algoritmos de inversão como os desenvolvidos pela Universidade da Columbia Britânica (UBC) e pelo professor M.H. Loke entre outros, aliado a facilidade atual de visualização tridimensional através de interpolações tipo Voxels (volumetric pixels) facilita em muito a separação das respostas do embasamento e do regolito. As figuras 7A e 7B são um exemplo claro disto.

Além de facilitarem o imageamento do embasamento, as inversões quantificam também as profundidades das fontes causadoras das anomalias observadas em 
superfície. Esta vantagem se torna muito importante principalmente na análise de dados magnéticos e gravimétricos. Devido à grande profundidade de investigação destas metodologias, na pesquisa mineral é muito importante trabalhar sobre fontes relativamente rasas, pensando na viabilidade econômica na fase de explotação do minério.

Até poucas décadas atrás, os métodos EM eram chamados de "bump finders". Uma alteração na condutividade do embasamento era localizada e investigada com outras metodologias exploratórias. Com o desenvolvimento de inversões EM que geram imagens tipo CDI (imagens de condutividade em profundidade), a metodologia EM passou a realmente agregar informação geológica em subsuperfície. No exemplo da figura 10 , uma CDI mostra em profundidade a geometria uma camada grafitosa, que neste caso específico é uma importante hospedeira de sulfetos ricos em ouro.

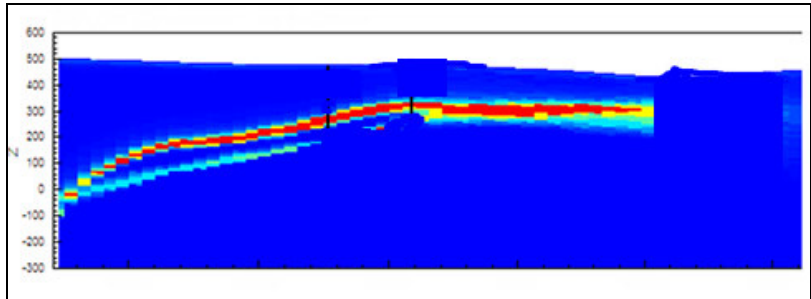

Figura 10 Imagem tipo $C D I$ de um perfil EM aéreo. $O$ condutor imageado refere-se a uma camada de xisto.

\section{Discussão e Conclusões}

Por ser um país situado em uma zona tropical, de alto regime erosivo, a maioria dos terrenos brasileiros estão cobertos por regolitos que impedem o estudo direto do embasamento rochoso. Tornando-se necessárias técnicas indiretas como as metodologias geofísicas.

A grande variedade dos regolitos no Brasil, tanto em composição como em espessura, impede que metodologias de sucesso em uma área tenham necessariamente o mesmo sucesso em outra região. Um entendimento mesmo que grosseiro das características do regolito local é fundamental para uma correta seleção dos métodos geofísicos ideais a serem aplicados, assim como o correto dimensionamento do arranjo a ser utilizado na aquisição.

Com exceção do método magnético aerotransportado, que é muito pouco suscetível a influência do manto de intemperismo, todos os demais métodos geofísicos são sempre passíveis de estarem contaminados por respostas vindas também do regolito.

O geocientista ao interpretar dados e imagens geofísicas no Brasil deverá questionar se as respostas que ele está observando estão refletindo variações das propriedades físicas do embasamento, do regolito ou de ambos somados.

As inversões atuais aliadas a facilidade de visualização tridimensional facilitam muito a separação das respostas vindas do embasamento e do regolito. Contudo, os modelos gerados sempre possuem limitações inerentes as condições de contorno dos algoritmos matemáticos utilizados. Estas limitações devem estar sempre claras durante processo de interpretação geológica dos modelos.

\section{Agradecimentos}

O autor agrade a RECONSULT GEOFÏSICA por financiar e permitir o desenvolvimento deste artigo.

\section{Referências}

Brandão, F.J.V., Porto C.G e Seoane, J.C.S. (2010). Mapeamento de regolito como ferramenta para exploração geoquímica de metais base no estado de Goiás. II Simpósio Brasileiro de Metalogenia.

Doyle, H.A. e Lindeman F.W. (1985). The effect of deep weathering on geophysical exploration in Australia - a review. Australian Journal of Earth Sciences, número 32, P 125-135.

Francke, J. Advances in geophysics to resource modeling of nickel laterites (2010). PDAC International Convention.

Palacky, G.J. e Kadekaru K. (1979). Effect of tropical weathering on electrical and electromagnetic measurements. Geophysics, volume 44, número 1. P 6988.

West, D e Witherly K. (1995). Geophysical exploration for gold in deeply weathered terrains. Exploration Geophysics, número 26, P124-130. 